\title{
KARAKTERISTIK BIO-OIL HASIL PIROLISIS AMPAS TEBU
}

\author{
CHARACTERISTICS OF BIO-OIL AS A YIELD OF BAGASSE PYROLYSIS
}

\author{
Emi Erawati $^{1}$, Wahyudi Budi Sediawan ${ }^{2}$, dan Panut Mulyono ${ }^{2}$ \\ I) Teknik Kimia-UMS Jl. A. Yani Tromol Pos I Pabelan Kartasura, Surakarta, Jawa Tengah, Indonesia \\ ${ }^{2)}$ Teknik Kimia - UGM, Jl. Grafika, Yogyakarta, Indonesia \\ Email: emi.erawati@ums.ac.id
}

Diterima: 19 Agustus 2013, Direvisi: 8 Agustus 2013, Disetujui: 20 September 2013

\begin{abstract}
ABSTRAK
Ampas tebu (Saccarum oficinarum L) merupakan limbah pabrik gula yang dapat dimanfaatkan untuk berbagai bahan kimia. Tujuan penelitian ini adalah mengetahui persentase senyawa-senyawa dan sifat-sifat fisik dari bio-oil, mengetahui pengaruh variasi diameter partikel dan kecepatan pemanasan terhadap hasil produk bio-oil.

Pirolisis dilakukan dalam reaktor yang terbuat dari pipa besi jenis 5737 dengan diameter 7,62 $\mathrm{cm}$ dan panjang $37 \mathrm{~cm}$. Reaktor dimasukkan ke dalam furnace yang berdiameter $15,24 \mathrm{~cm}$ dan panjang $40 \mathrm{~cm}$. Seratus lima puluh gram ampas tebu dimasukkan ke dalam reaktor tanpa adanya oksigen pada tekanan atmosfer. Pirolisis dilakukan pada diameter partikel $(-20+25)$ mesh, (-25+30) mesh, (-30+35) mesh, (35+40) mesh, dan -40 mesh dan tegangan listrik 100, 105, 115, dan 120 volt.

Bio-oil yang dihasilkan mempunyai sifatsifat: berwarna coklat, $\mathrm{pH}$ 2,96-3,03, viskositas 1,3306-1,5101 $\mathrm{cP}$, dan rapat massa 1,03-1,5 g/mL. Kandungan senyawa terbesar adalah asam asetat sebanyak 59,72\%. Pada variasi diameter partikel, \% hasil produk tertinggi diperoleh pada diameter partikel (20+25 mesh) sebesar 40,32\% sedangkan pada variasi tegangan listrik \% hasil produk tertinggi diperoleh pada kecepatan pemanasan 105 volt sebesar $38,82 \%$.
\end{abstract}

Kata kunci : Ampas tebu, asam asetat, bio-oil, pirolisis, hasil produk

\section{ABSTRACT}

Bagasse (Saccarum oficinarum L) is a waste of sugar mills that can be utilized for a variety of chemicals. The purposes of this study are to determine the percentage of compounds and physical properties of bio-oil, to determine the effect of variations of particle size and heating rate on the yields of bio-oil.

Pyrolysis has been carried out in a reactor made of steel pipe type 5737 with dimension: diameter $7.62 \mathrm{~cm}$ and a length of $37 \mathrm{~cm}$. The reactor was inserted into the furnace with a diameter of $15.24 \mathrm{~cm}$ and a length of $40 \mathrm{~cm}$. One hundred and fifty grams of bagasse (Saccarum oficinarum L) has been inserted into the reactor without the presence of oxygen at atmospheric pressure. Pyrolysis has been carried out at the particle size of $(-20+25)$ mesh, (-25+30) mesh, (-30+35) mesh, ($35+40)$ mesh, and -40 mesh with electrical voltage of 100, 105, 115, and 120 volt.

Produced of bio-oil has the following properties: brown color, pH of 2.96 to 3.03, viscosity of 1.3306 to $1.5101 \mathrm{cp}$, and density of 1.03 to $1.5 \mathrm{~g} / \mathrm{mL}$. The largest content of the compound is acetic acid (59,72\%). The highest yields percentage of the particle size is $(40,32 \%)$ on $(-20+25$ mesh) with the highest yields percentage of electrical voltage is $38,82 \%$ on 105 volt.

Keywords : Bagasse, acetic acid, bio-oil, pyrolysis, yields 


\section{PENDAHULUAN}

Ampas atau lazimnya disebut bagasse tebu adalah hasil samping dari proses ekstraksi (pemerahan) cairan tebu. Satu pabrik menghasilkan ampas tebu sekitar 35 - 40\% dari berat tebu yang digiling ${ }^{(1)}$. Berdasarkan data Pusat Penelitian Perkebunan Gula Indonesia (P3GI) ampas tebu yang dihasilkan sebanyak 32\% dari berat tebu giling. Pada musim giling 2006, data Ikatan Ahli Gula Indonesia (Ikagi) menunjukkan bahwa jumlah tebu yang digiling oleh 73 pabrik gula di Indonesia mencapai sekitar 30 juta ton. Sehingga ampas tebu yang dihasilkan diperkirakan mencapai 9.640.000 ton. Namun, baru $60 \%$ dari ampas tebu tersebut dimanfaatkan antara lain; sebagai bahan bakar, bahan baku untuk kertas, bahan baku industri kanvas rem, industri jamur, dan lain-lain. Oleh karena itu, diperkirakan sebanyak 40\% dari ampas tebu tersebut belum dimanfaatkan.

Peraturan Presiden Nomor 5 Tahun 2006 tentang Kebijakan Energi Nasional (KEN) menunjukkan adanya upaya agar pemakaian energi baru dan terbarukan meningkat. Energi baru adalah bentuk energi yang dihasilkan oleh teknologi baru baik yang berasal dari energi terbarukan maupun energi tak terbarukan, antara lain; hidrogen, coal bed methane, batubara yang dicairkan (liquefied coal), gasifikasi batubara (gasified coal), dan nuklir. Sedangkan energi terbarukan adalah sumber energi yang dihasilkan dari sumberdaya energi yang secara alamiah tidak akan habis dan dapat berkelanjutan jika dikelola dengan baik, antara lain panas bumi, bahan bakar nabati (biofuel), arus sungai, energi surya, energi angin, biomassa, dan energi laut.

Berdasarkan $^{(2)}$ Program Penelitian dan Pengembangan Ilmu Pengetahuan dan Teknologi, untuk biomassa menitikberatkan pada kegiatan studi kelayakan pembangkit listrik berbahan bakar campuran biomassa dan batubara untuk Pembangkit Listrik Tenaga Uap. Hal ini dilakukan karena potensi biomassa di seluruh Indonesia bila dikonversi menjadi energi listrik akan mencapai 1,160 MWe. Yang terdiri dari ampas tebu, limbah kelapa sawit, limbah pengergajian kayu, dan sekam padi. Pulau Sumatra mempunyai potensi biomassa paling tinggi, yaitu 590 MWe, berasal dari bagas tebu (40\%), limbah kelapa sawit (29\%), sisanya dari limbah penggergajian kayu, dan sekam padi. Potensi biomassa di pulau Jawa sebesar 280 MWe yang didominasi oleh ampas tebu dan sekam padi. Kalimantan berpotensi sebesar $230 \mathrm{MWe}$ dan Sulawesi 60 MWe. Walaupun begitu, pemanfaatan energi dari biomassa ini masih sangat rendah. Departemen Energi dan Sumber Daya Mineral Republik Indonesia menargetkan pada tahun 2025 Energi di Indonesia tidak hanya dipenuhi dari gas $(30 \%)$, oil $(20 \%)$, dan batubara (33\%), tetapi $17 \%$ energi di Indonesia akan disuplai melalui renewable energy. Salah satu renewable energy yang akan dikembangkan di Indonesia 
adalah energi yang berasal dari biomassa, nuklir, hydro power, solar, dan wind power sebesar 5\%. Dengan mengetahui prioritas Kebijakan Energi Nasional, Agenda Riset Nasional, dan Kebijakan Departemen Energi dan Sumber Daya Mineral Republik Indonesia, maka peneliti tertarik untuk melakukan penelitian karakterisik bio-oil hasil pirolisis ampas tebu (bagasse).

Manfaat yang diharapkan dari penelitian ini bagi ilmu pengetahuan, penelitian ini diharapkan dapat memberikan alternatif pemanfaatan ampas tebu sebagai bio-oil. Bagi bangsa dan negara, penelitian ini diharapkan membantu pemerintah dalam mencari sumber energi baru berbasis biomassa.

Tujuan dari penelitian ini adalah mengetahui persentase senyawa-senyawa dan sifat fisik dari bio-oil hasil pirolisis ampas tebu dan mengetahui pengaruh variasi diameter partikel dan kecepatan pemanasan pada yield bio-oil, hasil proses pirolisis.

Menurut P. Basu ${ }^{(3)}$ pirolisis adalah proses dekomposisi biomassa dari senyawa hidrokarbon rantai panjang menjadi molekul yang lebih sederhana. Berdasarkan prosesnya, pirolisis dibedakan menjadi fast pirolisis, medium pirolisis, dan slow pirolisis. Fast pirolisis yaitu pirolisis yang dilakukan pada suhu $\left( \pm 500^{\circ} \mathrm{C}\right)$, mempunyai waktu tinggal yang pendek $\quad(<2$ detik), menghasilkan $75 \%$ cairan, char $12 \%$, dan gas $13 \%$. Medium pirolisis yaitu pirolisis yang dilakukan pada suhu $\left(<500^{\circ} \mathrm{C}\right)$ dan mempunyai waktu tinggal yang terbatas ( \pm 2 detik), menghasilkan 50\% cairan, char $25 \%$, dan gas $25 \%$. Slow pirolisis yaitu pirolisis yang dilakukan pada suhu rendah, mempunyai waktu tinggal yang panjang (>2 detik), menghasilkan 30\% cairan, char 35\%, dan gas 35\%.

Bio-oil adalah senyawa anorganik yang merupakan cairan yang diproduksi melalui proses pirolisis ${ }^{(4)}$. Cairan yang berasal dari proses pirolisis diberi nama dengan cara yang berbeda-beda. Ada yang menyebut cairan pirolisis, minyak pirolisis (pyrolysis oil), biooil, cairan kayu (wood liquids), minyak kayu (wood oil), bio-crude-oil, bio-fuel-oil, liquid smoke, wood distillates, pyroligneous tar, pyroligneous acid, dan liquid wood.

Bio-oil mempunyai standar warna dari hijau gelap sampai dengan merah gelap mendekati hitam tergantung dari bahan dan proses yang digunakan untuk mendapatkan produk. Bio-oil tersusun dari berbagai komponen kimia dari bahan-bahan kimia yang mudah menguap seperti formaldehid, asam asetat, fenol, dan anhydrosugar. Berdasarkan penelitian DynaMotive, bio-oil yang dihasilkan mempunyai komposisi dan sifat fisik seperti yang ditunjukkan pada Tabel 1 dan Tabel $2^{(5)}$.

Kualitas dari bio-oil dengan warna coklat gelap jika dibandingkan dengan bahan biomassa mempunyai heating value seperti yang ditunjukkan pada Tabel 3. 
Tabel 1. Komposisi Bio-Oil

\begin{tabular}{lcc}
\hline Komposisi (\% berat) & Bagasse & Kayu Pine/Spruce 53\%+47\% Bark \\
\hline Air & 20,8 & 24,3 \\
\hline Lignin & 23,5 & 24,9 \\
\hline Cellobiosan & - & 1,9 \\
\hline Glyoxal & 2,2 & 1,9 \\
\hline Hidroksi asetaldehid & 10,2 & 10,2 \\
\hline Levoglukosan & 3,0 & 6,3 \\
\hline Formaldehid & 3,4 & 3,0 \\
\hline Asam format & 5,7 & 3,7 \\
\hline Asam asetat & 6,6 & 4,2 \\
\hline Acetol & 5,8 & 4,8 \\
\hline Tidak diketahui & 18,8 & 14,8 \\
\hline Total & 100 & 100 \\
\hline
\end{tabular}

Tabel 2. Sifat-Sifat Fisik Bio-Oil

\begin{tabular}{lcc}
\hline \multicolumn{1}{c}{ Sifat Fisik } & Bagasse & Kayu \\
\hline $\mathrm{pH}$ & 2,6 & 2,4 \\
\hline Air (\% berat) & 20,8 & 23,4 \\
\hline Lignin (\% berat) & - & 1,9 \\
\hline Padatan (\%) & $<0,10$ & $<0,10$ \\
\hline Abu (\% berat) & $<0,02$ & $<0,02$ \\
\hline Densitas (kg/L) & 1,20 & 1,19 \\
\hline Nilai kalor & 15,4 & 16,4 \\
\hline Viskositas & & \\
\hline pada $20^{\circ} \mathrm{C}$ & 57 & 78 \\
pada $80^{\circ} \mathrm{C}$ & 4,00 & 4,4 \\
\hline Bahan Baku & & 3,5 \\
\hline Kadar air (\%) & 2,1 & 3,5 \\
\hline Kadar abu (\%) & 2,9 & \\
\hline
\end{tabular}


JKTI, Vol. 15 No. 2, Desember 2013

Tabel 3. Perbandingan Nilai Panas Pembakaran Berbagai Bio-Oil

\begin{tabular}{ccccc}
\hline Bahan Baku & Corn cobs & Corn stover & Repeseed & Bunga matahari \\
\hline Nilai Kalor (MJ/kg) & 26,2 & 24,3 & 38,4 & 15,9 \\
\hline
\end{tabular}

DynaMotive dan Orenda Aerospace Corporation adalah perusahaan di New Hampshire, Durham, Amerika Serikat telah melakukan penelitian dengan mengoperasikan 2,5 MW mesin turbin dengan menggunakan bahan bakar bio-oil. Berdasarkan hasil uji, emisi CO dan partikulat lebih tinggi daripada solar, tetapi hasil uji emisi $\mathrm{NO}_{\mathrm{x}}$ dan $\mathrm{SO}_{2}$ lebih rendah daripada solar. Tabel 4 menunjukkan perbandingan sifat-sifat antara bio-oil dan solar. Nilai kalor bio-oil sekitar setengah daripada nilai kalor solar. Bio-oil yang dihasilkan mempunyai kadar air 20 (\% berat). Sehingga bio-oil yang dihasilkan bersifat hydrophilic dan immiscible. Kandungan alkali dalam bio-oil dapat menyebabkan korosi.

Tabel 4. Perbedaan Sifat-Sifat Bio-Oil dengan Solar

\begin{tabular}{lcc}
\hline \multicolumn{1}{c}{ Sifat-Sifat } & Bio-Oil & Solar \\
\hline Nilai kalor $(\mathrm{MJ} / \mathrm{kg})$ & $15-20$ & 42 \\
\hline Viskositas kinematik & 78 & $2-4$ \\
\hline $\mathrm{pH}$ & $2,3-3,3$ & 5 \\
\hline Air & $20-25(\%$ berat $)$ & $0,05(\%$ volume $)$ \\
\hline Padatan & $<0,1(\%$ berat $)$ & \\
\hline Abu & $<0,02$ & 0,01 \\
\hline Alkali $(\mathrm{Na}+\mathrm{K}) \mathrm{ppm}$ & $5-100$ & $<1$ \\
\hline
\end{tabular}

Tabel 4. Menunjukkan perbedaan sifatsifat bio-oil, light heavy fuel oil, dan heavy fuel oil. Bio-oil mempunyai nilai kalor viskositas, kadar abu, kadar belerang, kadar nitrogen, dan emisi $\mathrm{NO}_{\mathrm{x}}$ lebih rendah daripada

\section{BAHAN DAN METODA}

\section{Bahan}

Ampas tebu yang digunakan diambil dari Pabrik Gula (PG) Mojopanggung, Tulungagung, Jawa Timur. Ampas tebu yang digunakan dalam penelitian telah diuji di light fuel oil dan heavy fuel oil. Selain itu, biooil juga mempunyai keuntungan karena menghasilkan emisi $\mathrm{SO}_{\mathrm{x}}$ dan $\mathrm{NO}_{\mathrm{x}}$ hanya setengah daripada bahan bakar fosil.

Laboratorium Kimia dan Biokimia, Pusat Studi Pangan dan Gizi, Universitas Gadjah Mada.

\section{Peralatan}

Reaktor yang digunakan terbuat dari pipa 
besi jenis 5737 berdiameter 7,62 $\mathrm{cm}$ dan panjang $37 \mathrm{~cm}$. Bagian atas dari reaktor ditutup dengan isolator. Bagian luar reaktor dilapisi dengan isolator tungku (asbes pita). Reaktor dimasukkan ke dalam furnace yang berdiameter $15,24 \mathrm{~cm}$ dan panjang $40 \mathrm{~cm}$. Bagian luar dari furnace ditutup dengan isolator nikelin sepanjang 12 meter. Suhu di dalam reaktor diukur dengan termokopel. Kecepatan pemanasan dalam reaktor diukur dengan regulator 25 amper yang dihubungkan dengan arus listrik. Hasil cairan yang keluar dari reaktor didinginkan dengan kondensor pipa lurus. Hasil cair ditampung dalam penampung bio-oil. Gas yang tidak terkondensasi akan masuk ke dalam 2 galon yang berisi air masing-masing galon berukuran 19 liter. Gas yang keluar diukur suhunya dengan termokopel dan tekanannya dengan manometer terbuka. Volume gas yang dihasilkan ditampung dalam gelas ukur yang berukuran $2000 \mathrm{~mL}$ dan $3000 \mathrm{~mL}$.

\section{Metoda}

\section{Persiapan Bahan Baku}

Bahan baku dihaluskan dan diklasifikasi berdasarkan diameter partikel (dp) $(-20+25)$ mesh, $(-25+30)$ mesh, $(-30+35)$ mesh, (-35+40) mesh, dan -40 mesh. Kemudian bahan baku dikeringkan dengan oven selama 8 jam.

\section{Proses Pirolisis}

Bahan baku yang telah dioven ditimbang sebanyak 150 gram kemudian dimasukkan ke dalam reaktor dengan membuka bagian atas reaktor. Kabel termokopel dimasukkan ke dalam reaktor untuk mengukur suhu padatan selama proses pirolisis. Selanjutnya menutup reaktor dan memastikan tidak ada bagian yang bocor dengan menggunakan silicon white. Reaktor dimasukkan ke dalam furnace dan menyalakan reaktor dan termokontrol yang terhubung dengan arus listrik.

Cairan yang dihasilkan ditampung dalam penampung bio-oil. Proses pirolisis dihentikan jika massa bio-oil yang terbentuk mengalami perubahan kecil. Uji hasil bio-oil. Ulangi penelitian untuk variabel yang lain.

\section{Variabel Penelitian}

Penelitian dilakukan dengan variasi diameter partikel dan kecepatan pemanasan.

a. Diameter partikel (dp), yaitu: $(-20+25)$ mesh, $(-25+30)$ mesh, $(-30+35)$ mesh, (35+40) mesh, dan - 40 mesh.

b. Kecepatan pemanasan, yaitu: 100 volt, 105 volt, 110 volt, dan 120 volt.

\section{Analisis Bahan Baku}

Ampas tebu yang digunakan dalam penelitian diuji proximate analysis ${ }^{(6)}$. Menurut ${ }^{(2,7-9)}$, uji proximate analysis digunakan untuk mengetahui kandungan volatile matter, fixed carbon, ash, dan moisture. 


\section{Analisis Produk}

Menurut ${ }^{(11,12)}$ sifat-sifat fisik dari hasil cair berupa bio-oil dianalisis massa jenis, viskositas, nilai kalor, komposisi, dan warna.

\section{HASIL DAN PEMBAHASAN}

Bio-oil yang dihasilkan pada proses pirolisis mempunyai sifat-sifat yang dapat dilihat pada Tabel 5 dan 6 .

Kandungan senyawa dalam bio-oil hasil dari pirolisis bergantung pada jenis biomassa yang digunakan sebagai bahan baku. Pirolisis dengan bahan ampas tebu menghasilkan bio-oil dengan kandungan terbanyak senyawa asam asetat. Kandungan senyawa lain dapat dilihat pada Tabel 7 .
Berdasarkan Tabel 8 yield bio-oil turun dari $40,32 \%$ pada diameter $(-20+25)$ mesh menjadi $34,16 \%$ pada diameter partikel -40 mesh. Hal ini terjadi karena semakin kecil diameter partikel membuat panas mudah tersebar secara merata ke seluruh bagian. Semakin besar ukuran partikel pemanasan akan berlangsung lambat sehingga suhu rata-rata pada ampas tebu akan lebih rendah dan mengakibatkan yield yang diperoleh lebih sedikit. Menurut ${ }^{(3)}$ mengatakan bahwa dekomposisi dari biomassa akan menghasilkan condensable gas (uap) dan noncondensable gas. Uap yang terbentuk merupakan molekul yang mempunyai berat molekul besar yang akan didinginkan sehingga akan menambah yield dari bio-oil.

Tabel 5. Sifat-Sifat Fisik Bio-Oil pada Variasi Diameter

\begin{tabular}{|c|c|c|c|c|c|}
\hline \multirow[t]{2}{*}{ Parameter Uji } & \multicolumn{4}{|c|}{ Hasil } & \multirow[t]{2}{*}{ Metode } \\
\hline & $\begin{array}{c}(20+25) \\
\text { mesh }\end{array}$ & $\begin{array}{c}(25+30) \\
\text { mesh }\end{array}$ & $\begin{array}{c}(30+35) \\
\text { mesh }\end{array}$ & $\begin{array}{c}-40 \\
\text { mesh }\end{array}$ & \\
\hline $\mathrm{pH}(\mathrm{T})$ & $\begin{array}{c}2,96 \\
\left(25,5^{\circ} \mathrm{C}\right)\end{array}$ & $\begin{array}{c}2,96 \\
\left(25,8^{\circ} \mathrm{C}\right)\end{array}$ & $\begin{array}{c}3,03 \\
\left(29,9^{\circ} \mathrm{C}\right)\end{array}$ & $\begin{array}{c}2,09 \\
\left(24,8^{\circ} \mathrm{C}\right)\end{array}$ & SNI 06-6989.11-2004 \\
\hline Viskositas (cP) & 1,4015 & 1,3858 & 1,4593 & 1,4716 & Oswald \\
\hline Warna & & & dat & & Organoleptik \\
\hline $\begin{array}{l}\text { Massa jenis } \\
(\mathrm{g} / \mathrm{mL})\end{array}$ & $\begin{array}{c}1,043 \\
\left(28^{\circ} \mathrm{C}\right)\end{array}$ & $\begin{array}{l}1,0408 \\
\left(28^{\circ} \mathrm{C}\right)\end{array}$ & $\begin{array}{l}1,0352 \\
\left(25^{\circ} \mathrm{C}\right)\end{array}$ & $\begin{array}{l}1,0456 \\
\left(34^{\circ} \mathrm{C}\right)\end{array}$ & \\
\hline
\end{tabular}

Tabel 6. Sifat-Sifat Fisik Bio-Oil pada Variasi Kecepatan Pemanasan

\begin{tabular}{|c|c|c|c|c|c|}
\hline \multirow[t]{2}{*}{ Parameter Uji } & \multicolumn{3}{|c|}{ Hasil } & \multicolumn{2}{|r|}{ Metode } \\
\hline & 100 volt & 105 volt & 115 volt & 120 volt & \\
\hline \multirow[t]{2}{*}{$\mathrm{pH}(\mathrm{T})$} & 3,02 & 2,99 & 2,94 & 2,94 & SNI 06-6989.11-2004 \\
\hline & $\left(26,2^{\circ} \mathrm{C}\right)$ & $\left(26,6^{\circ} \mathrm{C}\right)$ & $\left(26,5^{\circ} \mathrm{C}\right)$ & $\left(26,1^{\circ} \mathrm{C}\right)$ & \\
\hline Viskositas (cP) & 1,4681 & 1,4129 & 1,5101 & 1,3306 & Oswald \\
\hline Warna & & Coklat & & & Organoleptik \\
\hline Massa jenis & 1,04 & 1,039 & 1,0649 & 1,041 & \\
\hline$(\mathrm{g} / \mathrm{mL})$ & $\left(34^{\circ} \mathrm{C}\right)$ & $\left(29^{\circ} \mathrm{C}\right)$ & $\left(30^{\circ} \mathrm{C}\right)$ & $\left(28^{\circ} \mathrm{C}\right)$ & \\
\hline
\end{tabular}


Tabel 7. Komposisi Senyawa di dalam Bio-Oil

\begin{tabular}{ccl}
\hline $\begin{array}{c}\text { Jumlah } \\
(\%)\end{array}$ & Rumus Molekul & \multicolumn{1}{c}{ Nama Senyawa } \\
\hline 59,72 & $\mathrm{CH}_{3} \mathrm{COOH}$ & Asam asetat \\
\hline 10,11 & $\mathrm{CH}_{4} \mathrm{O}$ & Metanol \\
\hline 5,07 & $\mathrm{C}_{6} \mathrm{H}_{6} \mathrm{O}$ & Fenol \\
\hline 4,8 & $\mathrm{C}_{3} \mathrm{H}_{6} \mathrm{O}_{2}$ & 2-Propanone, 1-hydroxy \\
\hline 3,72 & $\mathrm{C}_{3} \mathrm{H}_{6} \mathrm{O}_{2}$ & Asam propanoat \\
\hline 3,00 & $\mathrm{C}_{5} \mathrm{H}_{4} \mathrm{O}_{2}$ & 2-Furancarboxaldehyde \\
\hline 2,39 & $\mathrm{C}_{15} \mathrm{H}_{2} 6 \mathrm{O}$ & Patchouli alcohol \\
\hline 1,98 & $\mathrm{C}_{4} \mathrm{H}_{8} \mathrm{O}_{2}$ & 1-Hydroxy-2-butanone \\
\hline 1,84 & $\mathrm{C}_{5} \mathrm{H}_{6} \mathrm{O}$ & 2-Cyclopenten-1-one, 2-hydroxy-3-methyl \\
\hline 1,40 & $\mathrm{C}_{6} \mathrm{H}_{8} \mathrm{O}_{2}$ & 2-Cyclopenten-1-one, 2- \\
\hline 1,26 & $\mathrm{C}_{8} \mathrm{H}_{10} \mathrm{O}$ & Phenol, 3-ethyl \\
\hline 1,24 & $\mathrm{C}_{4} \mathrm{H}_{6} \mathrm{O}_{2}$ & 2(3H)-Furanone, dihydro \\
\hline 1,08 & $\mathrm{C}_{5} \mathrm{H}_{8} \mathrm{O}_{3}$ & 2-Propanone,1-(acetyloxy) \\
\hline 0,92 & $\mathrm{C}_{7} \mathrm{H}_{8} \mathrm{O}_{2}$ & Phenol, 2-methoxy \\
\hline 0,90 & $\mathrm{C}_{6} \mathrm{H}_{8} \mathrm{O}$ & 3-Methyl-2-cyclopenten-1-one \\
\hline 0,58 & $\mathrm{C}_{6} \mathrm{H}_{8} \mathrm{O}$ & 2-Methyl-2-cyclopenten-1-one \\
\hline
\end{tabular}

Tabel 8. Yields Bio-Oil Variasi Diameter Partikel

\begin{tabular}{cc}
\hline Diameter Partikel & \% Yields \\
\hline$(-20+25)$ mesh & 40,32 \\
\hline$(-25+30)$ mesh & 37,47 \\
\hline$(-30+35)$ mesh & 37,27 \\
\hline$(-35+40)$ mesh & 39,26 \\
\hline-40 mesh & 34,16 \\
\hline
\end{tabular}

Tabel 9. Yields Bio-Oil Variasi Kecepatan Pemanasan

\begin{tabular}{cc}
\hline Tegangan Listrik & \% Yields \\
\hline 100 volt & 33,31 \\
\hline 105 volt & 38,82 \\
\hline 115 volt & 37,00 \\
\hline 120 volt & 36,10 \\
\hline
\end{tabular}




\section{KESIMPULAN}

a. Bio-oil yang dihasilkan mempunyai sifat-sifat: berwarna coklat, $\mathrm{pH}$ 2,963,03, viskositas 1,3306-1,5101 cp, dan rapat massa 1,03-1,5 g/mL. Kandungan senyawa terbesar adalah asam asetat sebanyak $59,72 \%$.

b. Pada variasi tegangan listrik diperoleh yield bio-oil terbesar sebanyak $38,82 \%$, dan pada variasi diameter partikel diperoleh yield bio-oil 40,32\%, dan gas $17 \%$.

\section{DAFTAR PUSTAKA}

1. W.R. Susila, B.M. Sinaga, B.M., Analisis kebijakan pabrik gula di Indonesia. J. Agro Ekonomi. 23 : 29$52(2005)$

2. Agenda Riset Nasional, 2006-2009, Dewan Riset Nasional

3. P. Basu, 2010, Biomassa Gasification and Pyrolysis Practical Design and Theory, Elsevier, 2010.

4. M.E. Boucher, A. Chaala, H., Pakdel, C., Roy, 2000, Bio-oils obtained by vacuum pyrolysis of softwood bark as a liquid fuel for gas turbines. part ii: stability and ageing of bio-oil and its blends with methanol and a pyrolytic aqueous phase, J. Biomass and
Bioenergy, 19 : 351-361 (2000)

5. I.H. Farag, C.E. La Clair, and C.J. Barrett, C.J. Technical, Environmental and Economic Feasibility of Bio-Oil in New Hampshire's North Country", University of New Hampshire, Durham.

6. O. Onay, O.M. Kockar. Fixed-bed pyrolysis of rapeseed (Brassica napus L). J. Biomass and Bioenergy. 26 : 289-299 (2004)

7. J. Guo, A.C. Lua. Kinetic study on pyrolysis process of oil-palm solid waste using two-step consecutive reaction model. J. Biomass and Bioenergy, 17 : 223-233 (2001)

8. K.G. Mansaray, A.E. Ghalya, A.E. AlTaweel, A.M. Hamdullahpur, F., V.I Ugursal, Air gasification of rice husk in a dual distributor type fluidized bed gasifier, J. Biomass and Bionergy, 17 : 315-332 (1999).

9. S. Sensoz, D. Angin, S. Yorgun. 2000, Influence of particle size on the pyrolysis of rapeseed (brassica napus 1.): fuel properties of bio-oil. J. Biomass and Bioenergy 19 : 271-279 (2000)

10. A. Djauhari, A., Magister Thesis, Universitas Gadjah Mada. (2006)

11. 11.S. Sahraeni. Magister Thesis. Universitas Gadjah Mada. (2010) 